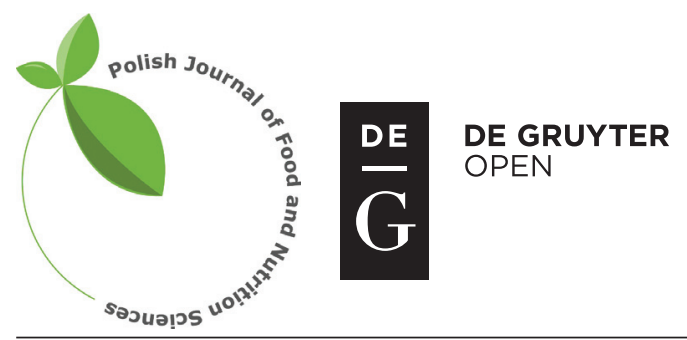

Pol. J. Food Nutr. Sci., 2016, Vol. 66, No. 4, pp. 287-293

DOI: $10.1515 /$ pjfns-2015-0055 http://journal.pan.olsztyn.pl

Original article

Section: Food Quality and Functionality

\title{
Application of Response Surface Methodology to Study the Combined Effect of Temperature, Time and pH on Antioxidant Activity of Cherry (Prunus avium) Honey
}

\author{
Gulzar Ahmad Nayik*, Vikas Nanda \\ Department of Food Engineering and Technology, Sant Longowal Institute \\ of Engineering and Technology, Longowal 148106 (Punjab) India
}

Key words: cherry honey, antioxidant activity, total phenolic content, total flavonoid content

\begin{abstract}
Response surface methodology (RSM) was employed to analyze the effect of independent variables viz. temperature, time and $\mathrm{pH}$ on antioxidant properties of cherry honey. Seventeen runs including five replicates were used to study the combined effect of temperature $\left(60-80^{\circ} \mathrm{C}\right)$, time (10-15 min) and $\mathrm{pH}$ (3 to 6) on the antioxidant properties [radical scavenging activity (DPPH-RSA), total phenolic content (TPC) and total flavonoid content (TFC)] of cherry honey. Statistical analysis revealed that process variables significantly affected all the responses. All the three parameters viz. DPPH-RSA, TPC and TFC increased with increase in time and temperature. The antioxidant properties of cherry honey were significantly decreased with increase in $\mathrm{pH}$ from 3 to 6 . The thermal treatment of honey at $80^{\circ} \mathrm{C}$ was found to be more effective than at 70 and $60^{\circ} \mathrm{C}$. The results demonstrated that antioxidant activity significantly increased with formation of browning pigments.
\end{abstract}

\section{INTRODUCTION}

According to the National Honey Board, [2010], Honey is a natural sweet, flavorful and miraculous product that has been appreciated as a functional food by humans owing to its uncountable medical and nutritional properties that have amplified interest and many scientific studies in recent years. Honey is the natural sweet substance produced by honey bees from the nectar of plants or from secretions of living parts of plants or excretions of plant-sucking insects on the living parts of plants, which the bees collect, transform by combining with specific substances of their own, deposit, dehydrate, store and leave in the honey comb to ripen and mature [Codex Alimentarius, 2001]. As a food, the honey has been used since ancient times however the evidences in the recent times proved its antioxidant activity. Honey has been found to display significant antioxidant activity due to the presence of both enzymatic (diastase, invertase, glucose oxidase) and non-enzymatic substances (phenolic acids, flavonoids, amino acids, organic acids). The main antioxidant activity is due to the presence of major polyphenols in the form of phenolic acids (chlorogenic, ferrulic, caffeic, ellagic, vanillic, benzoic, cinnamic, coumaric acid etc.) and flavonoids (pinocembrin, apigenin, hesperitin, chrysin, quercetin, luteolin, myricetin, pinobanksin, galangin, kaempferol etc.) [Gheldof \& Engeseth, 2002; Gheldof et al., 2002; Aljadi \& Kamaruddin, 2004;

\footnotetext{
* Corresponding Author: Cell: +91-9478153553/+91-9697470552 Fax: 01672-280057; E-mail: gulzarnaik@gmail.com (G. A. Nayik), vik164@yahoo.co.in (Vikas Nanda)
}

Baltrusaityte et al., 2007]. Such polyphenols have been known to exhibit much health benefiting properties (antiatherogenic, anticarcinogenic, antithrombotic, anti-inflammatory etc.). Besides polyphenols, a little contribution to antioxidant activity of honey is also done by Maillard reaction products, enzymes (catalase, peroxidase and glucose oxidase), carotenoids and vitamins (C and E) [Gheldof et al., 2002; Aljadi \& Kamaruddin, 2004]. The antioxidant activity of honey is dependent on floral as well as geographical origin [Beretta et al., 2005; Gheldof \& Engeseth, 2002; Gheldof et al., 2002]. Thus, honeys from different floral sources and regions differ in their antioxidant activity.

The response surface methodology (RSM) is a mathematical technique that has been verified as a valuable tool for determining the effect of response factor and the interactions among them. One of the major advantages of the RSM is reduction in the number of experiments required for evaluation and analysis. RSM is a faster and more efficient method for assembling research results than the classic one-variable at a time or full-factor experimentation. For a good fitted model, the coefficient of determination should not be less than $80 \%$. A higher value of $\mathrm{R}^{2}$, i.e. close to unity, indicated that the empirical model is suitable for fitting the actual data while a lower value of $\mathrm{R}^{2}$ means that the model is inappropriate for explaining the relation between variables [Little \& Hills, 1978; Mendenhall, 1975]. Normally, the raw honey undergoes processing before marketing as it contains some extraneous material (bee wax and pollen) which creates the problem of crystallization, thus such extraneous matter must be removed to make it marketable and acceptable to consumers. Therefore, 
the raw honey is subjected to thermal treatment mainly to prevent or delay crystallization and to destroy sugar-tolerant microorganisms that may cause unnecessary fermentation [Tosi et al., 2002; Escriche et al., 2008]. Although during thermal treatment, raw honey may lose most of its natural antioxidants but the formation of non-nutrient antioxidants like Maillard reaction products (MRPs) can compensate such loss [Manzocco et al., 2000; Nicoli, 1997]. A few studies on the impact of thermal treatment on the antioxidant activity of honey are available [Wang et al., 2004; Turkmen et al., 2006], but no study have been done so far on the combined effect of time, temperature and $\mathrm{pH}$ on the antioxidant properties of honey. Thus, the main objective of this study was to analyze the effect of time, temperature and $\mathrm{pH}$ on the antioxidant activity of cherry honey by using response surface methodology.

\section{MATERIAL AND METHODS}

\section{Chemicals and reagents}

Methanol, acetic acid, Folin-Ciocalteu reagent, DPPH, $\mathrm{AlCl}_{3}$, sodium acetate (trihydrate) and sodium carbonate were procured from Fluka Goldie, Mumbai, India.

\section{Honey sample collection and pollen analysis}

The raw honey samples of cherry (Prunus avium) were collected from local beekeepers, packed and sealed in glass bottles and stored at $4^{\circ} \mathrm{C}$. The authenticity of cherry honey samples was confirmed by melissopalynology. Honey samples were classified according to their botanical origin using the method described by Von der Ohe et al. [2004]. The following terms were used for frequency classes: predominant pollen ( $>45 \%$ of pollen grains counted), secondary pollen $(16-45 \%)$, important minor pollen $(3-15 \%)$ and minor pollen $(<3 \%)$.

\section{Heat treatment}

The honey was heated at different temperatures (60$-80^{\circ} \mathrm{C}$ ) for different time periods $(10-15 \mathrm{~min})$ with different $\mathrm{pH}$ values ranging from 3 to 6 using acetate buffer solutions $(0.1 \mathrm{~mol} / \mathrm{L}$ of sodium acetate and $0.1 \mathrm{~mol} / \mathrm{L}$ of acetic acid $)$. The honey samples, weighed in small glass containers, were placed in a water bath at desired temperature with a thermocouple placed in the sample to monitor its internal temperature. Once the internal temperature reached the desired temperature, the sample was cooled to $20^{\circ} \mathrm{C}$. The samples were analyzed in duplicate for total phenolic content (TPC), total flavonoid content (TFC) and antioxidant activity by DPPH assay.

\section{Determination of total phenolic and flavonoid content}

To determine the total phenolics content present in all honey samples, Folin-Ciocalteu method was employed. The total phenolic content was determined by comparing with the standard curve using gallic acid $(0-100 \mu \mathrm{g} / \mathrm{mL})$. The results were expressed as mg of gallic acid equivalents (mg GAE)/100 g of honey. For total flavonoid determination, Dowd method was used, modified by Arvouet-Grand et al. [1994]. The total flavonoid content was determined by comparing with a standard curve prepared using quercetin $(0-100 \mu \mathrm{g} / \mathrm{mL})$.
The means of three readings were calculated and the results were expressed as mg quercetin/100 g honey (mg QE/100 g).

\section{DPPH radical scavenging activity (DPPH-RSA)}

The DPPH radical-scavenging assay based on the ability of antioxidants to block the 2,2-diphenyl-1-picrylhydrazyl radical was used to measure the antioxidant activity in the honey samples. The DPPH radical scavenging activity was determined according to the method adopted by Meda et al. [2005]. In brief, $0.6 \mathrm{~g}$ of honey sample was dissolved in $4 \mathrm{~mL}$ of methanol. After this $1.5 \mathrm{~mL}$ of DPPH reagent solution $(0.02 \mathrm{mg} / \mathrm{mL})$ was added to $0.75 \mathrm{~mL}$ of honey solution and the samples were kept in the dark for $15 \mathrm{~min}$ at room temperature. The absorbance of the mixture was measured at $517 \mathrm{~nm}$ against methanol blank by using Spectrophotometer (Hach Lange DR6000 UV-VIS, Dusseldorf Germany). The radical scavenging activity of DPPH radical expressed as $\%$ inhibition was calculated from the following equation:

$$
\% \text { Inhibition }=\frac{\left(\mathrm{Abs}_{\text {control }}-\mathrm{Abs}_{\text {sample }}\right)}{\mathrm{Abs}_{\text {control }}} \times 100
$$

where $\mathrm{Abs}_{\text {control }}$ is the absorbance of control (1.50 mL DPPH and $0.75 \mathrm{~mL}$ methanol) at $517 \mathrm{~nm}$ and $\mathrm{Abs}_{\text {sample }}$ is the absorbance of sample at $517 \mathrm{~nm}$

\section{Experiment design}

For the design of experimental combinations, RSM was adopted [Montgomery, 2002] by using Design-Expert version 9.0.4 (Statease Inc., Minneapolis, MN, USA) to test the combined effect of three variables [temperature $\left(60-80^{\circ} \mathrm{C}\right)$, time (10-15 min) and $\mathrm{pH}(3-6)]$ on three responses (DPPH-RSA, TPC and TFC ) of cherry honey. Thus a three factor and three level Box-Behnken design [Tekindal et al., 2012] consisting of thirteen experimental runs at center point was employed. The data were analyzed by multiple regressions using the least-squares method. A second-order polynomial equation was fitted to data which is given below:

$$
\begin{gathered}
Y_{k}=\beta_{o}+\beta_{1} x_{1}+\beta_{2} x_{2}+\beta_{3} x_{3+} \beta_{11} x_{1}^{2}+\beta_{22} x_{2}^{2}+\beta_{33} x_{3}^{2}+ \\
+\beta_{12} x_{1} x_{2}+\beta_{13} x_{1} x_{3}+\beta_{23} x_{2} x_{3}
\end{gathered}
$$

where $\mathrm{Y}_{\mathrm{k}}=$ response variable, $\mathrm{Y}_{1}=\mathrm{DPPH}-\mathrm{RSA}(\%), \mathrm{Y}_{2}=\mathrm{TPC}$ $\left(m g\right.$ GAE/100g) $Y_{3}=$ TFC $(m g Q E / 100 g), x_{1} x_{2}$ and $x_{3}$ represent the coded independent variables for temperature $\left({ }^{\circ} \mathrm{C}\right)$, time ( $\mathrm{min}$ ) and $\mathrm{pH}$ and respectively. $\beta_{\mathrm{o}}$ was the value of the fitted response at the center point of the design that is point $(0,0,0) . \beta_{1-3}$ and $\beta_{11-33}$ were the linear and quadratic regression coefficients respectively while $\beta_{12}, \beta_{13}$ and $\beta_{23}$ were cross-product regression coefficients. The test of statistical significance was performed on the total error criteria with a confidence level of $95 \%$. The significant terms for each response in the model were determined by using ANOVA. $\mathrm{R}^{2}$, Pred. $\mathrm{R}^{2}$ and adj- $\mathrm{R}^{2}$ were used to check the efficiency of the model.

\section{RESULTS AND DISCUSSION}

The percentages of pollen spectra are related to pollens of nectar-producing plants. Cherry honey (Prunus avium) 
TABLE 1. Effect of independent variables (temperature, time and pH) on responses (DPPH activity, total phenolic content (TPC) and total flavonoid content (TFC) of cherry honey.

\begin{tabular}{|c|c|c|c|c|c|c|}
\hline $\begin{array}{l}\text { Experiment } \\
\text { No. }\end{array}$ & $\begin{array}{c}\text { Temperature } \\
\left({ }^{\circ} \mathrm{C}\right) \mathrm{X}_{1}\end{array}$ & $\begin{array}{c}\text { Time } \\
(\min ) X_{2}\end{array}$ & $\begin{array}{l}\mathrm{pH} \\
\mathrm{X}_{3}\end{array}$ & $\begin{array}{c}\mathrm{DPPH} \\
(\%)\end{array}$ & $\begin{array}{c}\text { TPC } \\
\text { (mg GAE/100g) }\end{array}$ & $\begin{array}{c}\text { TFC } \\
\text { (mg QE/100g) }\end{array}$ \\
\hline 1 & 60.00 & 12.50 & 3.00 & 69.45 & 95.13 & 14.68 \\
\hline 2 & 70.00 & 15.00 & 3.00 & 69.89 & 103.23 & 17.9 \\
\hline 3 & 70.00 & 12.50 & 4.50 & 67.59 & 99.58 & 17.16 \\
\hline 4 & 80.00 & 10.00 & 4.50 & 73.18 & 100.99 & 19.65 \\
\hline 5 & 80.00 & 15.00 & 4.50 & 74.14 & 100.23 & 21.35 \\
\hline 6 & 70.00 & 12.50 & 4.50 & 67.7 & 99.12 & 17.3 \\
\hline 7 & 70.00 & 12.50 & 4.50 & 67.65 & 100.03 & 17.32 \\
\hline 8 & 70.00 & 15.00 & 6.00 & 70.75 & 95.63 & 17.8 \\
\hline 9 & 70.00 & 12.50 & 4.50 & 67.73 & 100.82 & 17.25 \\
\hline 10 & 70.00 & 12.50 & 4.50 & 67.71 & 99.19 & 17.22 \\
\hline 11 & 60.00 & 10.00 & 4.50 & 68.59 & 91.49 & 15.93 \\
\hline 12 & 60.00 & 12.50 & 6.00 & 68.6 & 92.28 & 13.03 \\
\hline 13 & 70.00 & 10.00 & 3.00 & 70.22 & 95.41 & 16.82 \\
\hline 14 & 80.00 & 12.50 & 3.00 & 73.39 & 101.57 & 17.52 \\
\hline 15 & 70.00 & 10.00 & 6.00 & 69.02 & 97.81 & 17.44 \\
\hline 16 & 80.00 & 12.50 & 6.00 & 74.01 & 104.11 & 20.15 \\
\hline 17 & 60.00 & 15.00 & 4.50 & 69.50 & 93.76 & 15.46 \\
\hline
\end{tabular}

All response values are mean values of duplicates.

possessed 46-57\% pollen of Prunus avium, which confirmed its unifloral authenticity. Further authenticity was confirmed by quantification and identification of volatile compounds using SPME-GCMS in our previous study [Nayik \& Nanda, 2015]. The DPPH-RSA, TPC and TFC of raw cherry honey were $67.42 \%, 88.91 \mathrm{mg} \mathrm{GAE} / 100 \mathrm{~g}$ and $11.42 \mathrm{mg} \mathrm{QE} / 100 \mathrm{~g}$, respectively. The responses of antioxidant activity (DPPH-RSA), total phenolic content (TPC) and total flavonoid content (TFC) obtained from the experiments are listed in Table 1. The ANOVA data for response variables and their significance at $95 \%$ confidence level along with their correlation coefficient is presented in Table 2. A large regression co-efficient and a small P-value would indicate a more significant effect on the respective response variables for any of the terms in the model. ANOVA showed that the resulting quadratic model were adequately suitable showing significant regression, no lack of fit, low residual values with coefficients of multiple determinations $\left(\mathrm{R}^{2}\right)$ of $0.99,0.96$ and 0.99 for the responses viz. DPPH-RSA, TPC and TFC, respectively. Table 3 shows second order regression coefficients for responses (DPPH-RSA, TPC and TFC) of cherry honey. A large value of $\mathrm{R}^{2}$ does not always imply the sufficiency of the model. For this reason, use of an adjusted- $\mathrm{R}^{2}$ of over 90\% to evaluate the model adequacy is implemented. For all the responses viz. DPPH-RSA, TPC and TFC, the adj-R ${ }^{2}$ was found to be more than 0.90 . Higher adj- $R^{2}$ indicated that nonsignificant terms have not been included in the model.
TABLE 2. Significant levels of cherry honey responses using RSM.

\begin{tabular}{lcccc}
\hline $\mathrm{P}>\mathrm{F}$ & $\begin{array}{c}\text { DPPH activity } \\
(\%)\end{array}$ & $\begin{array}{c}\mathrm{TPC} \\
(\mathrm{mg} \mathrm{GAE} / 100 \mathrm{~g})\end{array}$ & $\begin{array}{c}\mathrm{TFC} \\
(\mathrm{mg} \mathrm{QE} / 100 \mathrm{~g})\end{array}$ \\
\hline Model & $<0.0001$ & 0.0003 & $<0.0001$ \\
$\begin{array}{l}\text { A: Temperature } \\
\left({ }^{\circ} \mathrm{C}\right)\end{array}$ & $<0.0001$ & $<0.0001$ & $<0.0001$ \\
$\mathrm{~B}$ : Time (min) & $<0.0001$ & 0.0472 & $<0.0001$ \\
$\mathrm{C}: \mathrm{pH}$ & 0.0382 & 0.1065 & 0.0009 \\
$\mathrm{~A}^{2}$ & $<0.0001$ & 0.0263 & 0.0151 \\
$\mathrm{~B}^{2}$ & $<0.0001$ & 0.0131 & $<0.0001$ \\
$\mathrm{C}^{2}$ & $<0.0001$ & 0.9452 & $<0.0001$ \\
$\mathrm{AB}$ & 0.7608 & 0.1930 & $<0.0001$ \\
$\mathrm{AC}$ & $<0.0001$ & 0.0374 & $<0.0001$ \\
$\mathrm{BC}$ & $<0.0001$ & 0.0021 & 0.0069 \\
$\mathrm{R}^{2}$ & 0.9995 & 0.9650 & 0.9990 \\
Adjusted $\mathrm{R}^{2}$ & 0.9989 & 0.9199 & 0.9976 \\
Pred. R & 0.9941 & 0.9277 & 0.9876 \\
Adeq. Precision & 106.013 & 15.525 & 114.885 \\
Lack of Fit & 0.1428 & 0.1097 & 0.1131 \\
\hline
\end{tabular}


TABLE 3. Second order regression coefficients for responses (DPPH, TPC and TFC) of cherry honey.

\begin{tabular}{lccccccc|c|c|c|c|c}
\hline Response & Intercept & $\mathrm{A}$ & $\mathrm{B}$ & $\mathrm{C}$ & $\mathrm{AB}$ & $\mathrm{AC}$ & $\mathrm{BC}$ & $\mathrm{A}^{2}$ & $\mathrm{~B}^{2}$ & $\mathrm{C}^{2}$ \\
\hline DPPH & 67.68 & 2.32 & 0.41 & -0.071 & -0.012 & 0.37 & 0.52 & 2.53 & 1.14 & 1.15 \\
TPC & 99.75 .60 & 4.28 & 0.89 & -0.69 & -0.76 & 1.35 & -2.50 & -1.44 & -1.69 & 0.036 \\
TFC & 17.25 & 2.45 & 0.33 & 0.19 & 0.54 & 1.07 & -0.18 & -0.15 & 1.00 & -0.76 \\
\hline
\end{tabular}

Where $\mathrm{A}=$ Temperature; $\mathrm{B}=$ time; $\mathrm{C}=\mathrm{pH}$.

\section{Response surface analysis of antioxidant activity (DPPH-RSA)}

Table 2 demonstrated the response surface analysis (RSA) of the data between the temperature and independent variables is quadratic, with a very good regression coefficient $\left(\mathrm{R}^{2}=0.99\right)$. Figure la-c shows the combined effect of temperature, time and $\mathrm{pH}$ on antioxidant activity of cherry honey. Temperature showed a positive linear and positive quadratic effect on the DPPH-RSA ( $<<0.0001, p<0.0001)$. The DPPH-RSA of cherry honey increased with increase in time and temperature (Figure 1a) which could be due to the formation of Maillard reaction products (MRPs). MRPs exhibit significant antioxidant properties as previously reported in various foods [Giovanelli \& Lavelli, 2002; Wagner et al., 2002]. The increase in antioxidant activity of cherry honey was more significant at $80^{\circ} \mathrm{C}$ than those at 60 and $70^{\circ} \mathrm{C}$, which indicated a large reliability of the antioxidant activity on thermal treatment. Depending on processing conditions and composition of food product, the formation of different compounds in non-enzymatic browning reactions proceed through different chemical pathways which could be attributed of logarithmic increase of antioxidant activity at $80^{\circ} \mathrm{C}$ [Manzocco et al., 2000; Van Boekel, 2001]. Similar results for antioxidant activity were obtained by Turkmen et al. [2006] and Calligaris et al. [2004] in prolonged heating of honey and milk, respectively. Our results were also consistent with the findings of Fauzi et al. [2014] who reported that high pressure processing with thermal treatment caused significant increase in antioxidant activity of Manuka honey from New Zealand. The $\mathrm{pH}$ also plays a vital role in antioxidant activity of honey. The $\mathrm{pH}$ showed a negative linear $(\mathrm{p}<0.0382)$ and positive quadratic effect $(<0.0001)$ with temperature on the DPPH activity. Figure $1 \mathrm{~b}$ shows that with increase in acidity, i.e. from $\mathrm{pH} 6$ to 3 and increase in temperature range from 60 to $80^{\circ} \mathrm{C}$, the DPPH-RSA increases. The reason could be the gain of $\mathrm{H}+$ ions upon fall in $\mathrm{pH}$. The combined effect of time (10 to $15 \mathrm{~min}$ ) and $\mathrm{pH}$ (3-6) also decreased the antioxidant activity due to the loss of $\mathrm{H}+$ ions upon rise in $\mathrm{pH}$ (Figure 1c). Figure 2 clearly demonstrated that the experimental results and the predicted values of DPPH-RSA were not significantly different.

\section{Response surface analysis of total phenolic content (TPC)}

Table 2 demonstrated the response surface analysis (RSA) of the data with a very good regression coefficient $\left(\mathrm{R}^{2}=0.96\right)$. TPC was significantly influenced by temperature, time and $\mathrm{pH}$. Temperature and time showed a positive linear effect and a negative quadratic effect on the TPC $(p<0.0001)$. Similar to antioxidant activity, increase in time and tempera- ture lead to increase in TPC as shown in Figure 3a, which may be due to the formation of antioxidant-rich non-enzymatic products (MRPs) in honey, since the antioxidant activity of honey is mainly due to polyphenols [Nayik \& Nanda, 2015]. The combined effect of $\mathrm{pH}$-temperature and $\mathrm{pH}$-time on TPC of cherry honey is shown in Figure $3 b$ and $3 c$, respectively. With increase in temperature from 60 to $80^{\circ} \mathrm{C}$ and increase in $\mathrm{pH}$ from 6 to 3 (i.e. increase in acidity), TPC increased because at lower $\mathrm{pH}$, phenolic compounds will have less susceptibility towards oxidation as hydroxyl groups would be shielded by protonation. Thus, antioxidant activity of cherry honey is affected by $\mathrm{pH}$. The experimental values of the total phenolic content are slightly lower than the predicted values as shown in Figure 4.

\section{Response surface analysis of total flavonoid content (TFC)}

The response surface analysis (RSA) of the TFC data with a very good regression coefficient $\left(\mathrm{R}^{2}=0.99\right)$ is shown in Table 2. Similar to the effect experienced by TPC, the TFC was also significantly influenced by process variables (Figure 5a-c). Temperature and $\mathrm{pH}$ showed a positive linear effect and negative quadratic effect while time showed both positive effects for linear as well as for quadratic. As described above that the antioxidant activity of honey is mainly due to presence of polyphenols, thus the effect of temperature showed the same effect as that of DDPH-RSA activity, i.e. with increase in time and temperature, TFC also increased (Figure $5 \mathrm{a})$. Figure $5 \mathrm{~b}$ demonstrated that with increase in temperature from 60 to $80^{\circ} \mathrm{C}$ and increase in $\mathrm{pH}$ from 6 to 3, there is increase in TFC of cherry honey. The TFC was more significant at acidic $\mathrm{pH}$ since, in acidic $\mathrm{pH}$, the antioxidant activity of polyphenols is more significant and would decrease monotonously with increase in $\mathrm{pH}$ from 3 to 6 , due to deprotonation of hydroxyl groups. The experimental and predicted values of total flavonoid content were not significantly different (Figure 6).

\section{CONCLUSION}

RSM was employed to study the combined effect of time, temperature and $\mathrm{pH}$ on antioxidant activity of cherry honey. The study proved that the antioxidant activity of honey is greatly affected by thermal treatment and $\mathrm{pH}$. In both TPC and TFC, the conversion of phenolic groups into hydroxide radicals upon rise in $\mathrm{pH}$ from 3 to 6 , caused the decrease in antioxidation activity due to loss of $\mathrm{H}+$ ions. The study showed that at acidic $\mathrm{pH}$, there is significant antioxidant activity of cherry honey. 

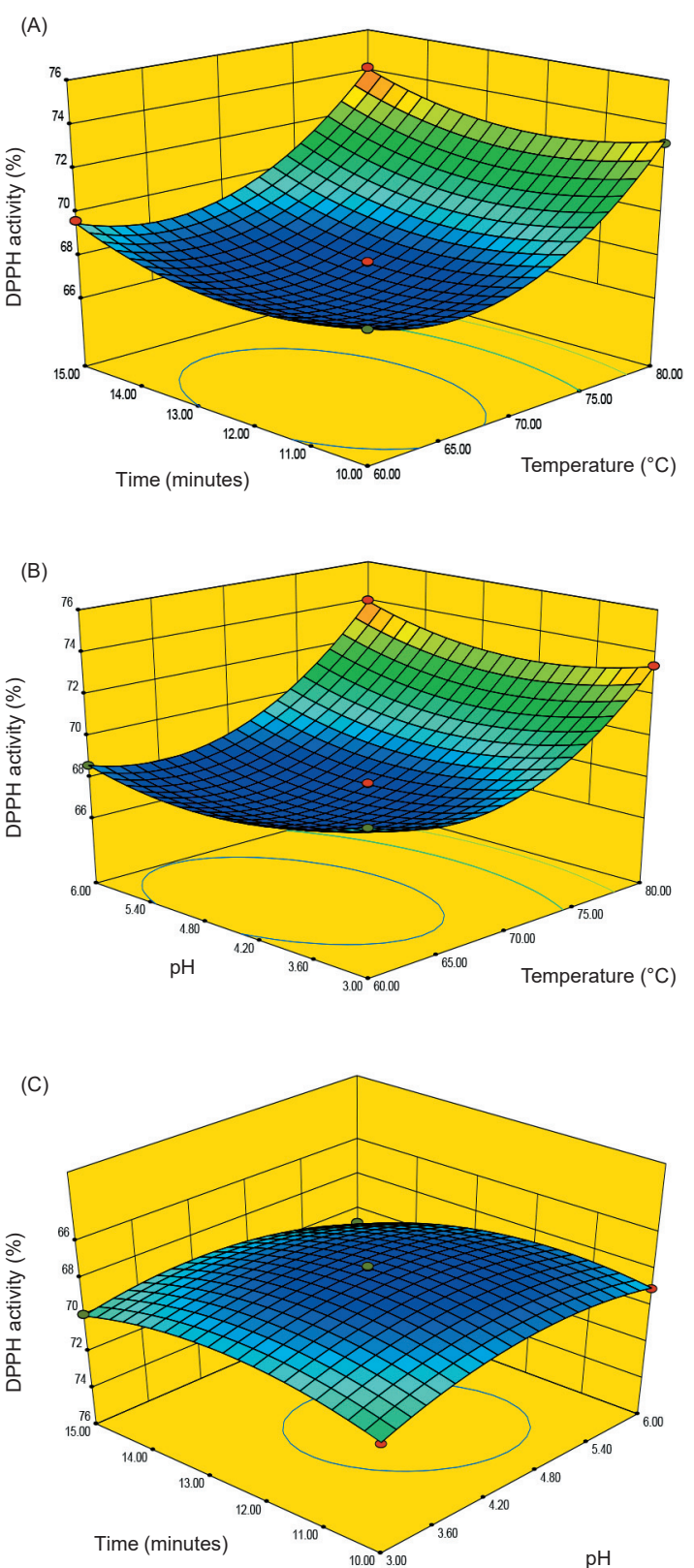

FIGURE 1. Response surface plot of DPPH activity as a function of (a) time and temperature, (b) $\mathrm{pH}$ and temperature (c) time and $\mathrm{pH}$.

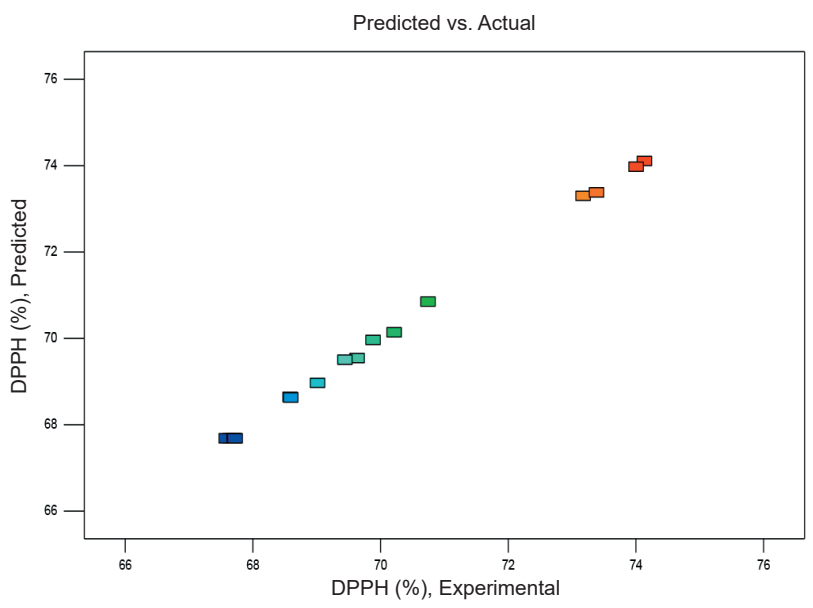

FIGURE 2. Comparison of the experimental values of DPPH activity with predicted values.
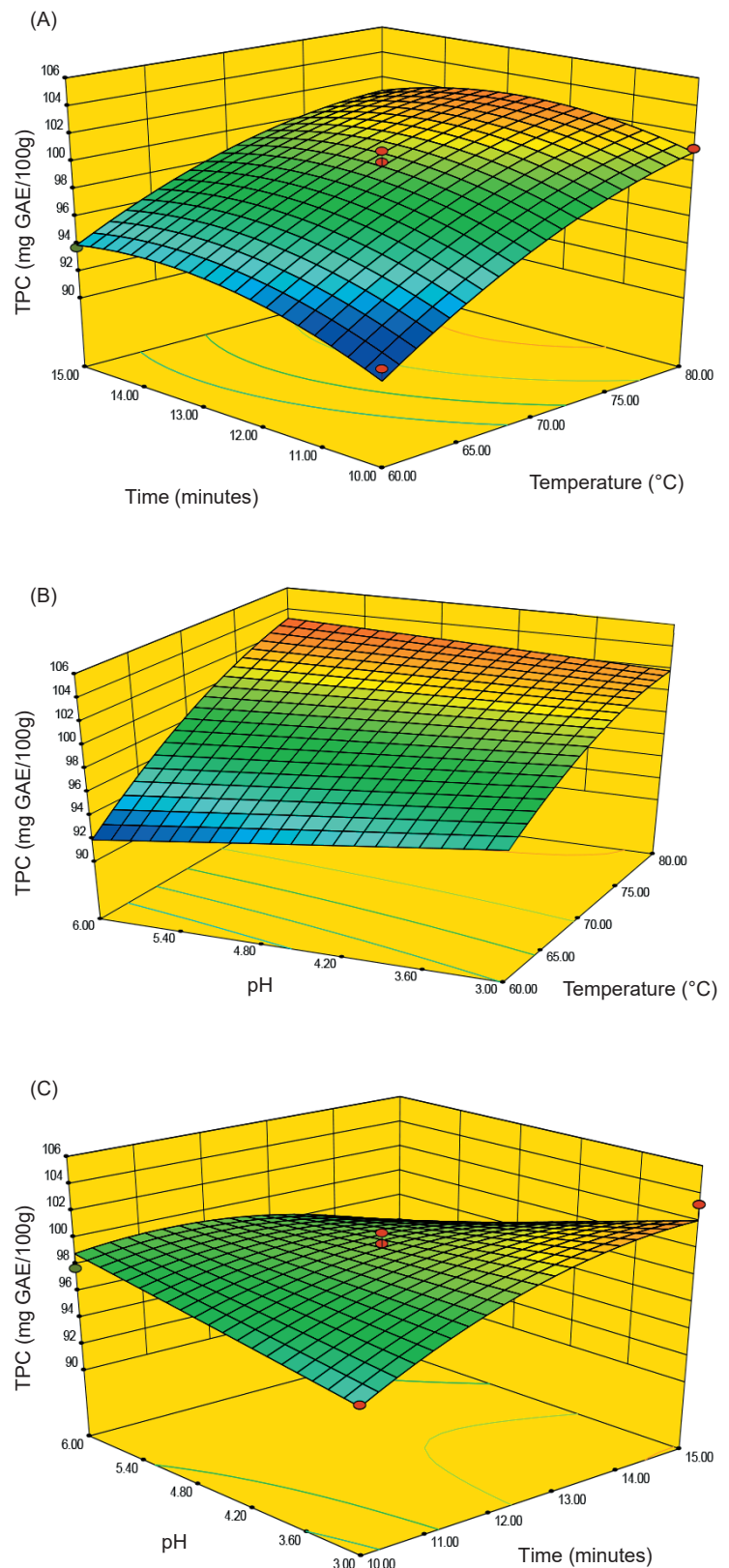

FIGURE 3. Response surface plot of TPC as a function of (a) time and temperature, (b) $\mathrm{pH}$ and temperature (c) time and $\mathrm{pH}$.

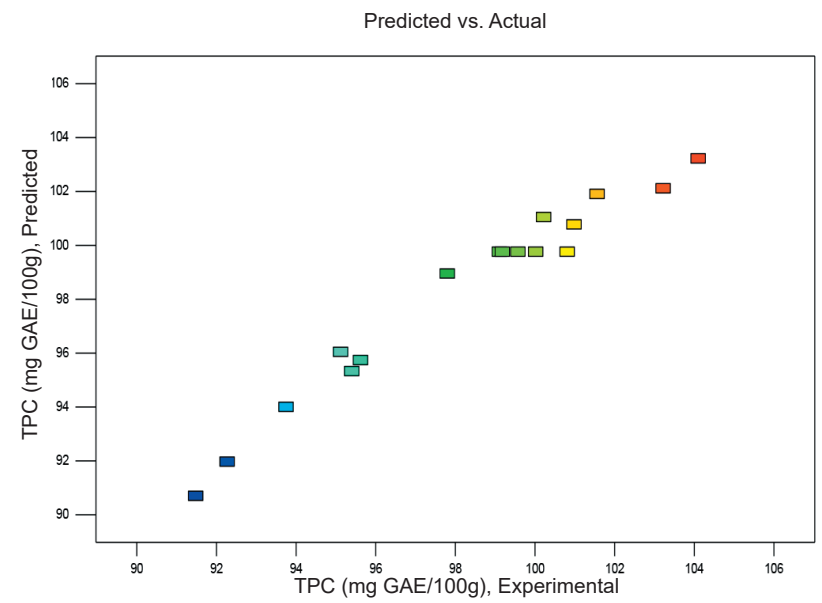

FIGURE 4. Comparison of the experimental values of TPC with predicted values. 

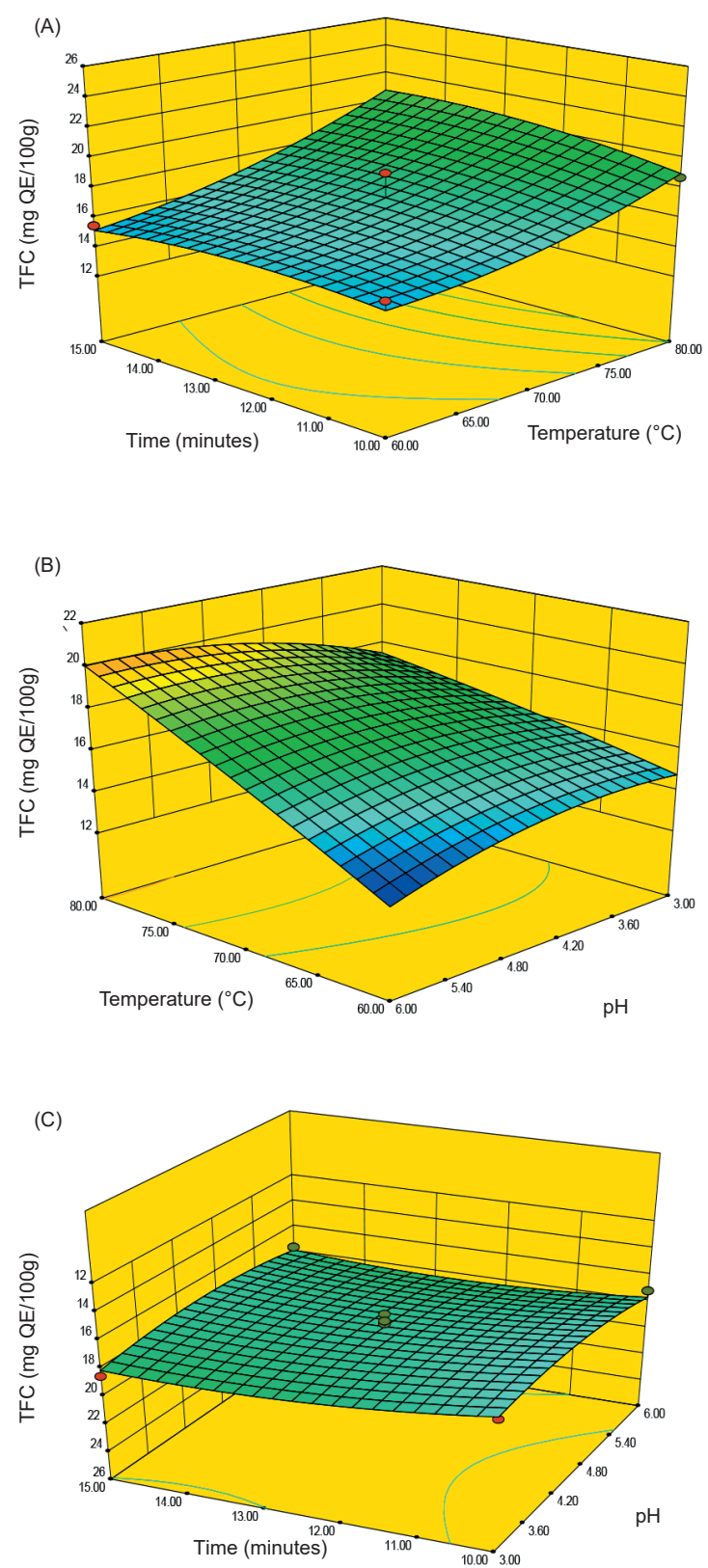

FIGURE 5. Response surface plot of TFC as a function of (a) time and temperature, (b) $\mathrm{pH}$ and temperature (c) $\mathrm{pH}$ and time.

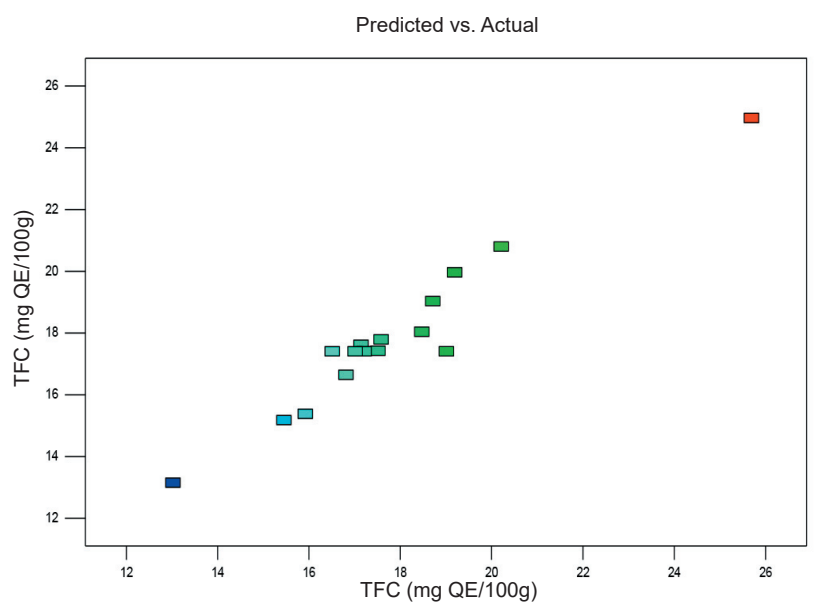

FIGURE 6. Comparison of the experimental values of TFC with predicted values.

\section{ACKNOWLEDGEMENTS}

The first author is very much thankful to local beekeepers of Kashmir valley of India for providing raw honey samples and also to UGC New Delhi for providing financial assistance in the form of MANF-2013-14.

\section{REFERENCES}

1. Aljadi A. M., Kamaruddin M.Y., Evaluation of the phenolic contents and antioxidant capacities of two Malaysian floral honeys. Food Chem., 2004, 85, 513-518.

2. Arvouet-Grand A., Vennat B., Pourrat A., Legret P., Standardization d'une extrait de propolis et identification des principaux constituents. J. de Pharam. de Belg. 1994, 49, 462-468 (in French).

3. Baltrusaityte V., Venskutonis P.R., Ceksteryte, V., Radical scavenging activity of different floral origin honey and beebread phenolic extracts. Food Chem., 2007, 101, 502-514.

4. Beretta G., Granata, P., Ferrero M., Orioli M., Facino R.M., Standardization of antioxidant properties of honey by a combination of spectrophotometric/fluorometric assays and chemometrics. Anal. Chim. Acta., 2005, 533, 180-191.

5. Calligaris S., Manzocco L., Anese M., Nicoli M.C., Effect of heat-treatment on the antioxidant activity and pro-oxidant activity of milk. Int. Dairy J., 2004, 14, 421-427.

6. Codex Alimentarius. Standard for honey. Codex Alimentarius Commission FAO/OMS Rome, 2001, 1-8.

7. Escriche I., Visquert M., Carot J.M., Domenech E., Fito P., Effect of honey thermal conditions on hydroxymethylfurfural content prior to pasteurization. Food Sci. Technol. Int., 2008, 14, 29-35.

8. Fauzi N.M., Farid M.M., Silva F.V.M., High-pressure processing of manuka honey: Improvement of antioxidant activity, preservation of colour and flow behavior. Food Bioproc. Technol., 2014, 7, 2299-2307.

9. Gheldof N., Engeseth N.J., Antioxidant capacity of honeys from various floral sources based on the determination of oxygen radical absorbance capacity and inhibition of in vitro lipoprotein oxidation in human serum samples. J. Agric. Food Chem., 2002, 50, 3050-3055.

10. Gheldof N., Wang X.H., Engeseth N.J., Identification and quantification of antioxidant components of honeys from various floral sources. J. Agric. Food Chem., 2002, 50, 5870-5877.

11. Giovanelli G., Lavelli V., Evaluation of heat and oxidative damage during storage of processed tomato products. I. Study of heat damage indices. J. Sci. Food Agric., 2002, 82, 1263-1267.

12. Little T.M., Hills F.J., Agricultural Experimentation Design and Analysis, 1978, John Wiley, New York.

13. Manzocco L., Calligaris S., Mastrocola D., Nicoli M.C., Lerici C.R., Review of non-enzymatic browning and antioxidant capacity in processed foods. Trends Food Sci. Technol., 2000, 11, 340-346.

14. Meda, A., Lamien, C.E., Romito, M., Millogo, J., Nacoulma, O.G. Determination of the total phenolic, flavonoid and proline contents in Burkina Fasan honey, as well as their radical scavenging activity. Food Chem., 2005, 91, 571-577.

15. Mendenhall, W., Introduction to Probability and Statistics, 1975, $4^{\text {th }}$ ed. Duxbury Press, North Settuate, MA, p.273.

16. Montgomery, D.C., Design and Analysis of Experiments, Response Surface Methodology, 2002, $5^{\text {th }}$ ed., Wiley, New York, pp. 416-419. 
17. National Honey Board, Honey Varietals, 2010. Available at: [http://www.honey.com].

18. Nayik G.A., Nanda V., Physico-chemical, Enzymatic, Mineral and colour characterization of three different varieties of honeys from Kashmir valley of India with a multivariate approach. Pol. J. Food Nutr. Sci., 2015, 65(2), 101-108.

19. Nayik G.A., Nanda V., Characterization of the volatile profile of unifloral honey from Kashmir valley of India by using solidphase microextraction and gas chromatography-mass spectrometry. Eur. Food Res. Tech., 2015, 240, 1091-1100.

20. Nicoli M.C., Anese M., Parpinel M.T., Franceschi S., Lerici C.R., Loss and/or formation of antioxidants during food processing and storage. Cancer Lett., 1997, 114, 71-74.

21. Tekindal M.A., Bayrak H., Ozkaya B., Genc Y., Box- Bssehnken experimental design in factorial experiments: the importance of bread for nutrition and health. Turkish J. Field Crops., 2012, $17,115-123$.

22. Tosi E., Ciappini M., Re E., Lucero H., Honey thermal treatment effects on hydroxymethylfurfural content. Food Chem., 2002, 77, 71-74.
23. Turkmen N., Sari F., Poyrazoglu E. S., Velioglu Y.S., Effects of prolonged heating on antioxidant activity and colour of honey. Food Chem., 2006, 95, 653-657.

24. Van Boekel M.A.J.S., Kinetics aspects of the Maillard reaction: a critical review. Nahrung/Food., 2001, 45, 150-159.

25. Von Der Ohe W., Oddo L.P., Piana M.L., Morlot M., Martin P., Harmonized methods of melissopalynology. Apidologie., 2004, $35,18-25$

26. Wagner K.H., Derkits S., Herr M., Schuh W., Elmadfa I., Antioxidative potential of melanoidins isolated from a roasted glucoseglycine model. Food Chem., 2002, 78, 375-382.

27. Wang X.H., Gheldof N.N., Engeseth J., Effect of processing and storage on antioxidant capacity of honey. J. Food Sci., 2004, 69, 96-101.

Submitted: 30 May2015. Revised: 23 October 2015. Accepted: 7 December 2015. Published on-line: 1 March 2016. 
